\title{
DESIGN OF CIRCULARLY POLARIZED SLOT PATCH ANTENNA FOR C-BAND APPLICATIONS
}

\author{
Jyoti Singhal and M.P. Turuk \\ Department of Electronics and Telecommunication Engineering, Pune Institute of Computer Technology, India
}

\begin{abstract}
Circularly Polarized (CP) antennas are becoming increasingly popular for wireless applications. This paper describes design and simulation of circularly polarized slot patch antenna for $C$-band applications. $C$ band has frequency range from 4 to $8 \mathrm{GHz}$ that is used for satellite communication transmissions, some Wi-Fi devices, and cordless telephone. For circular polarization, the axial ratio (AR) less than $3 \mathrm{~dB}$ can be produced by inserting a rectangular stub from the ground plane towards the square shaped slot. The simulation results are observed by Ansoft HFSS version 13 software in terms of return loss, VSWR, axial ratio and radiation pattern. Simulated results show that the antenna attains an $S_{11}<-10 \mathrm{~dB}$, return loss bandwidth from $(4 \mathrm{GHz}$ to $8 \mathrm{GHz})$ and the axial ratio bandwidth from $(4.5 \mathrm{GHz}$, to $7.3 \mathrm{GHz})$. The proposed micro-strip slot patch antenna is connected by $50 \Omega$ micro-strip feed line and it has been fabricated on FR4 Substrate.
\end{abstract}

Keywords:

Circularly Polarized, Slot Antenna, Axial Ratio

\section{INTRODUCTION}

Now-a-days, there is an increasing demand for wireless communication systems. Hence, researchers are trying to develop small antennas with various modifications in radiating elements and feed structure. Circularly polarized antennas have various advantages over linearly polarized antennas such as better mobility and weather penetration [1].

In this case, the construction of the (CP) antennas working in $\mathrm{C}$ band is becoming increasingly popular. $\mathrm{C}$-Band is a radio frequency band from 4-8GHz. Because of such high frequency, the antenna size needs not to be very large. There are many applications working in $\mathrm{C}$ band such as WLAN, Mobile, WiMAX and WCDMA.

The circular polarization can be obtained by exciting two orthogonal modes with equal amplitude and a phase difference of 90 degrees. This is done by providing dual feed to the patch [2]. Circular polarization can also be produced by inserting symmetric and asymmetric slots in the patch such as a wide slot, a ring slot, multiple $L$ shaped ground strips, etc. [3].

In this Paper, two patch antennas such as Antenna 1(Linear polarization) and Antenna 2 (Circular Polarization) with slots are designed. Antenna 1 has a slot in ground plane. The antenna 1 provides linear polarization. To get circular polarization, two rectangular stubs are introduced from the ground plane towards the centre of the slot. This forms the design of antenna 2. The performance parameters of both the antennas are compared.

The section 2 discusses the antenna design. The section 3 provides the design specification. The section 5 and 6 discusses the results and discussions of antenna 1 and 2, respectively. Section 7 discusses the results from the measurement of VNA.
Section 8 provides the comparative results between antenna 1 and 2. Finally, section 9 concludes the paper.

\section{ANTENNA DESIGN}

\subsection{ANTENNA 1 DESIGN}

A Microstrip slot antenna is a metal patch with a hole or slot cut out in it. The design of the antenna 1 is shown in Fig.1. It has a rectangular slot in the ground plane. The designed antenna is fed by a micro-strip line feed with impedance of $50 \Omega$. The substrate used is $\mathrm{FR}_{4}\left(\varepsilon_{r}=4.4\right.$, thickness $\left.h=1.6 \mathrm{~mm}\right)$. The ground plane is at the bottom of the substrate. A slot is introduced in the ground plane of the antenna.

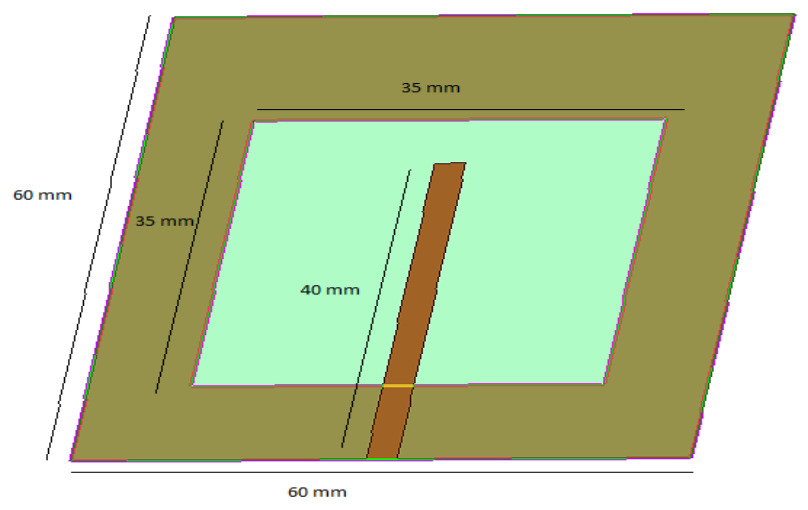

Fig.1. Design of Antenna 1

\subsection{ANTENNA 2 DESIGN}

Antenna 2 has same dimensions and material used as in antenna 1 . In addition, two horizontal stubs are introduced from the ground plane towards the mid of the slot so that it can achieve circular polarization.

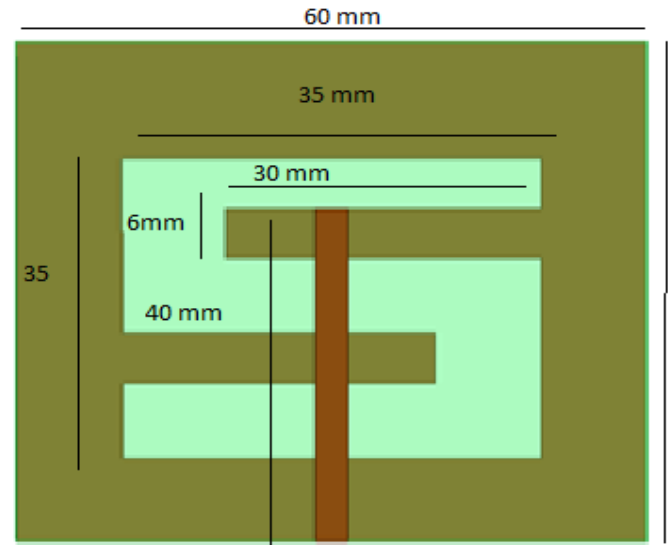

$60 \mathrm{~mm}$

Fig.2. Design of Antenna 2 


\section{DESIGN SPECIFICATIONS}

The dimensions of designed antennas are as given in Table.1.

Table.1. Dimensions of Antennas 1 and 2

\begin{tabular}{|c|c|}
\hline Parameter & Values \\
\hline Desired resonant frequency & $5.4 \mathrm{GHz}$ \\
\hline Dimensions of substrate & $60 \mathrm{~mm} \times 60 \mathrm{~mm}$ \\
\hline Dimensions of ground plane & $60 \mathrm{~mm} \times 60 \mathrm{~mm}$ \\
\hline Dielectric substrate & $\mathrm{FR}_{4}$ epoxy \\
\hline Dielectric constant of substrate $\left(\varepsilon_{r}\right)$ & 4.4 \\
\hline Height of substrate & $1.6 \mathrm{~mm}$ \\
\hline Length of feed line & $40 \mathrm{~mm}$ \\
\hline Width of feed line & $3 \mathrm{~mm}$ \\
\hline Length of slot in the ground plane & $35 \mathrm{~mm}$ \\
\hline Width of slot in the ground plane & $35 \mathrm{~mm}$ \\
\hline Length of stubs in antenna 2 & $30 \mathrm{~mm}$ \\
\hline Width of stubs in antenna 2 & $6 \mathrm{~mm}$ \\
\hline
\end{tabular}

\section{RESULTS AND DISCUSSIONS OF ANTENNA-1}

The designed antennas are simulated in the software Ansoft HFSS version 13.0. Simulated results like return loss $\left(S_{11}\right)$, VSWR, Axial ratio (AR), Impedances and gain for required antenna are shown in the Fig.3 to Fig. 10.

- Return loss $\left(S_{11}\right)$ of Antenna 1: The Fig.3 shows the Return loss $\left(S_{11}\right)$ of Antenna 1 . The antenna resonating at $6 \mathrm{GHz}$ with Return loss of $-13.51 \mathrm{~dB}$.

- VSWR of Antenna 1: The Fig.4 shows the VSWR of Antenna 1.

- Axial Ratio (AR) of Antenna 1: Graph of Axial Ratio (AR) of Antenna 1 is as shown in Fig.5. The Axial ratio at resonant frequency of $6 \mathrm{GHz}$ is $46.9 \mathrm{~dB}$, which is greater than $3 \mathrm{~dB}$ $(46.9 \mathrm{~dB})$. Hence the Antenna 1 is linearly polarized with VSWR of 1.53 .

\section{RESULTS AND DISCUSSIONS OF ANTENNA-2}

- Return Loss $\left(S_{11}\right)$ of Antenna 2: The Fig.6 shows the Return loss of Antenna 2. The antenna resonates at $5.4359 \mathrm{GHz}$ with return loss of $-16.64 \mathrm{~dB}$.

- Voltage Standing Wave Ratio of Antenna 2: The Fig. 7 shows the Voltage Standing Wave Ratio (VSWR) of Antenna 2. Antenna resonates at $5.4359 \mathrm{GHz}$ with VSWR of 1.5 .

- VSWR of Antenna 2: The Fig.7 shows the VSWR of Antenna-1.

- Axial Ratio (AR) of Antenna 2: The axial ratio (AR) of Antenna 2 is as shown in Fig.8. The axial ratio (AR) at resonant frequency of $5.4359 \mathrm{GHz}$ is $2.2913 \mathrm{~dB}$. It is less than $3 \mathrm{~dB}$. Hence, the antenna 2 is circularly polarized.

- Impedance of Antenna 2: The Fig.9 shows that the impedance of Antenna 2. The antenna resonating at $5.4 \mathrm{GHz}$ with impedance of $55.4 \Omega$.

- Gain of Antenna 2: The Fig.10 shows gain of Antenna 2. The antenna resonates at $5.4 \mathrm{GHz}$ with gain of $1.37 \mathrm{~dB}$.

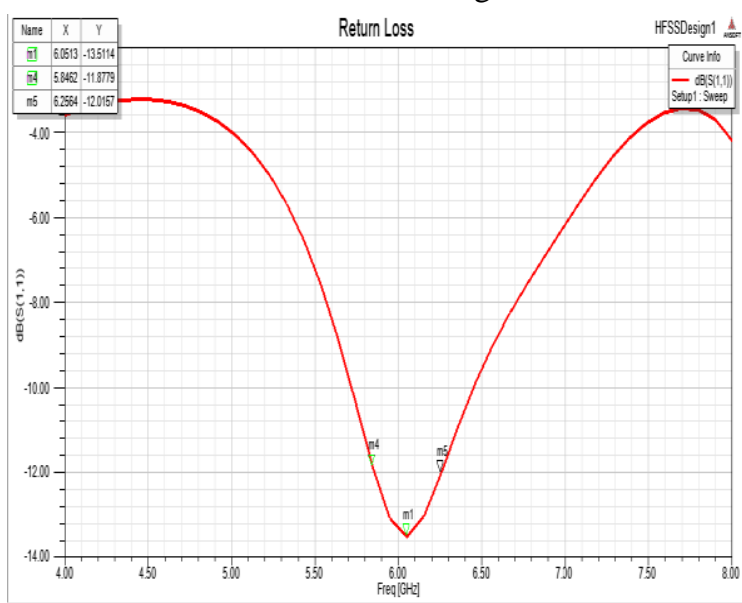

Fig.3. Return Loss of Antenna 1

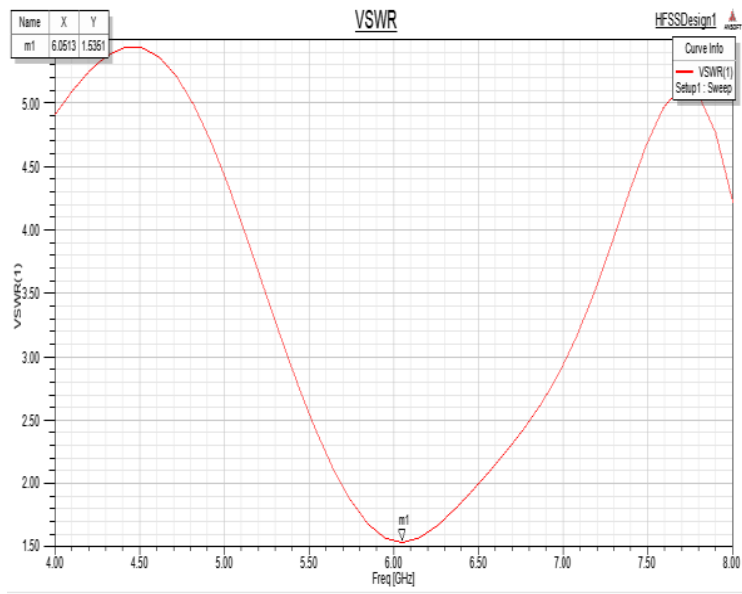

Fig.4. VSWR of Antenna 1

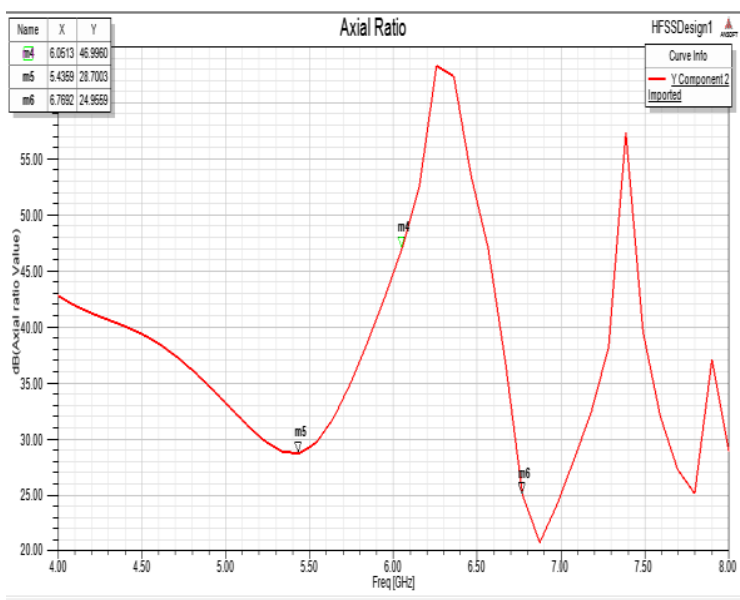

Fig.5. Axial Ratio (AR) of Antenna 1 


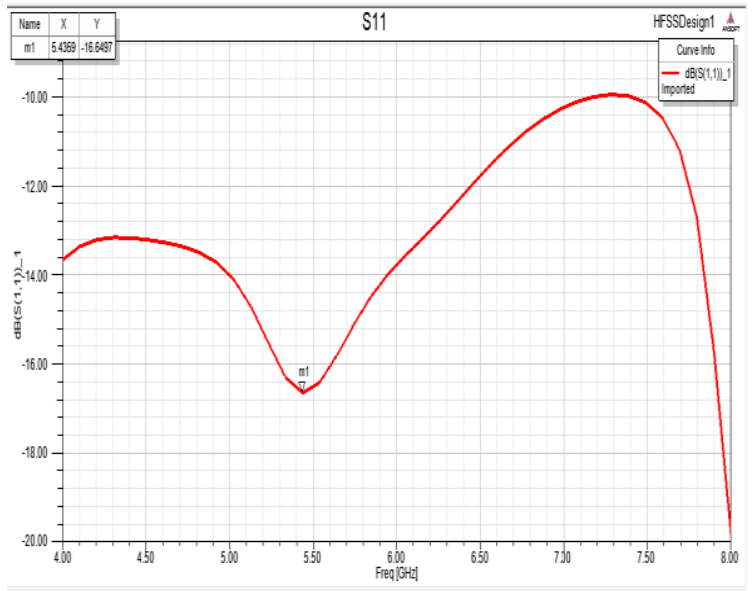

Fig.6. Return Loss $\left(S_{11}\right)$ of Antenna 2

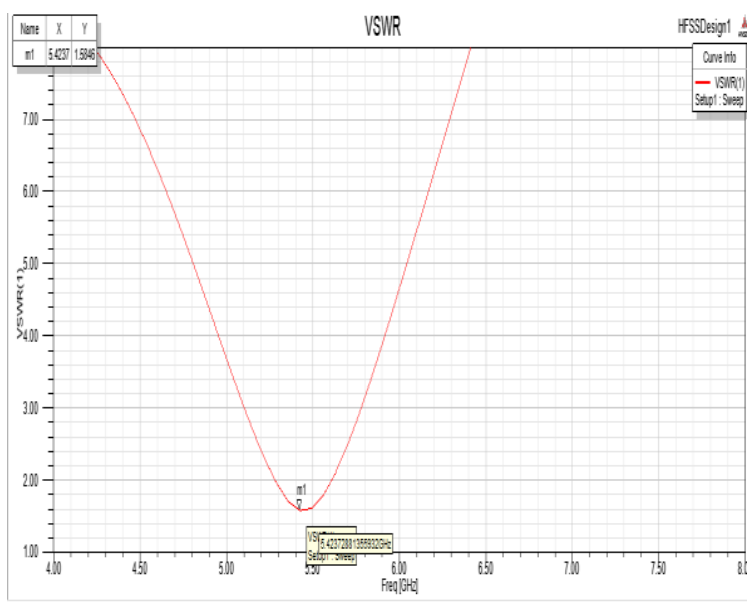

Fig.7. VSWR of Antenna 2

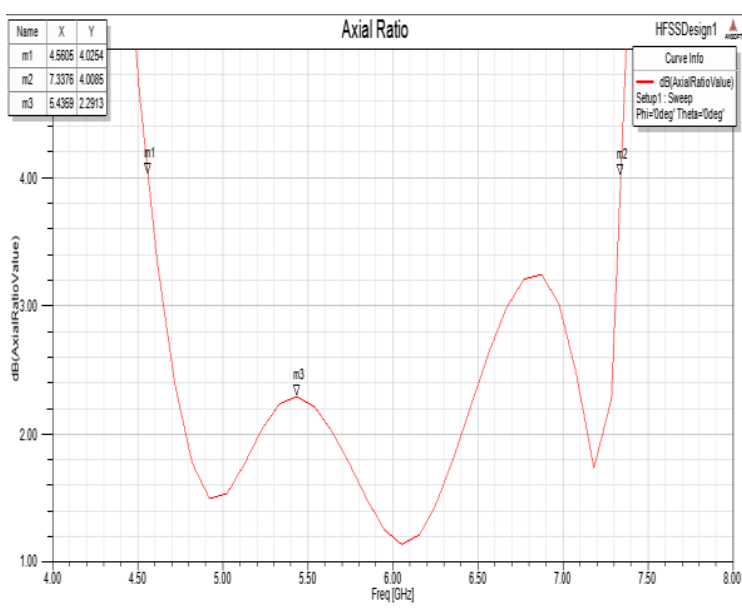

Fig.8. Axial Ratio (AR) of Antenna 2

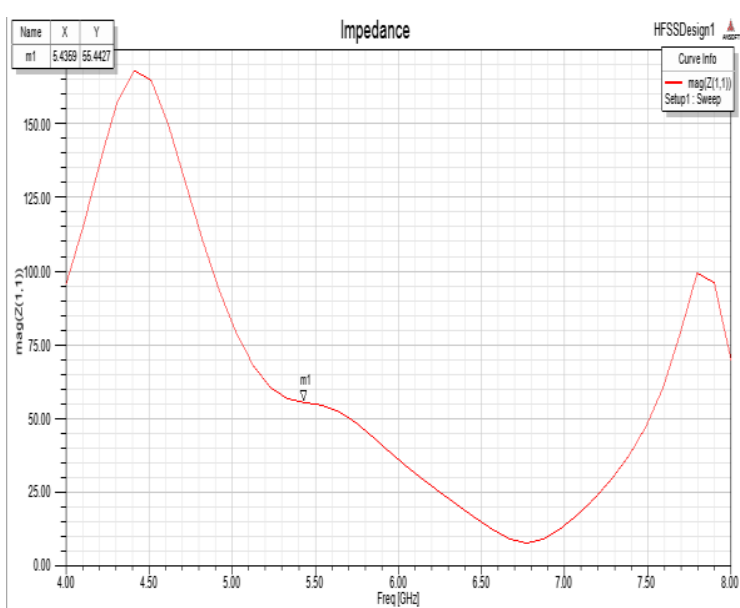

Fig.9 Impedance of Antenna 2

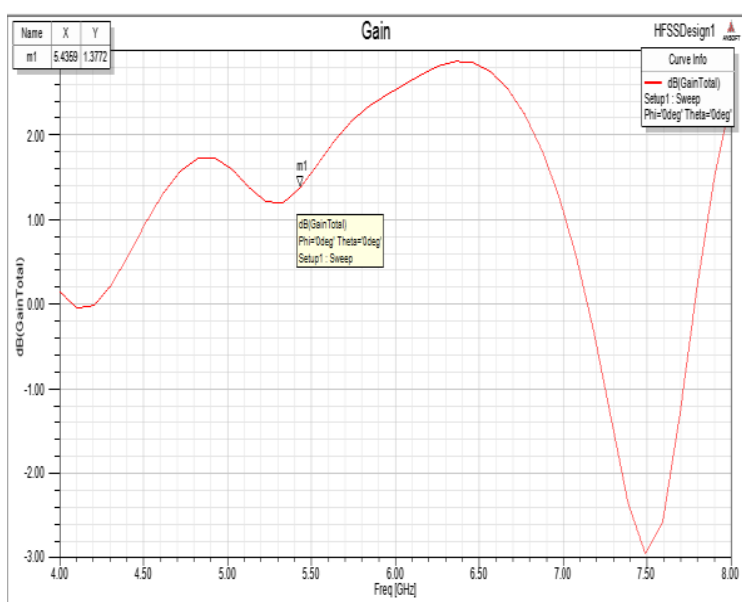

Fig.10. Gain of Antenna 2

\section{RESULTS FOR FABRICATED ANTENNAS}

All the simulated antennas with respect to dimensions are fabricated with desired design frequency and tested using vector network analyzer. Two Antennas where fabricated. In fabrication process FR4 material used as substrate material are of thickness $3 \mathrm{~mm}$. SMA connector is used to provide to feed the antenna. The Fig. 11 shows the linearly Polarized Antenna with $\mathrm{FR}_{4}$ substrate is fabricated for 6GHz. In Fig. 12 shows the Circularly Polarized Antenna for $5.4 \mathrm{GHz}$.

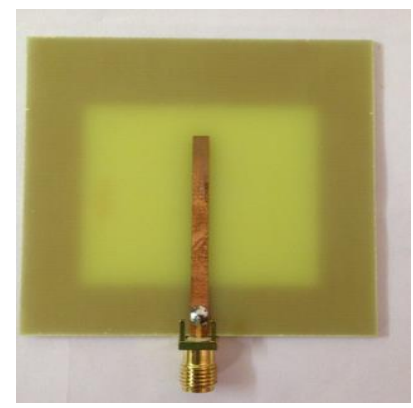

Top View

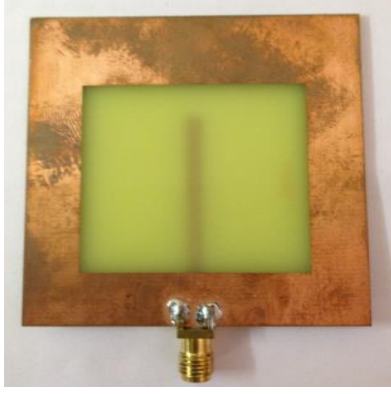

Bottom View
Fig.11. Fabricated Antenna 1 with FR4 substrate for $6 \mathrm{GHz}$ 


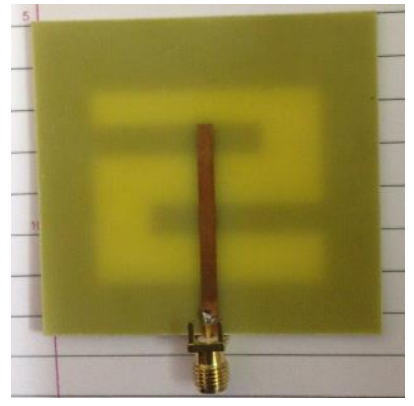

Top View

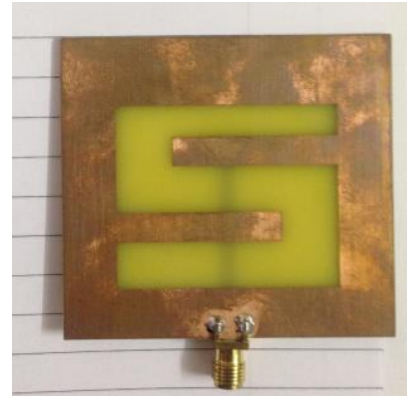

Bottom View
Fig.12. Fabricated Antenna 2 with $\mathrm{FR}_{4}$ substrate for $5.4 \mathrm{GHz}$

The image of fabricated antennas shown in Fig.11 and the Fig.12 and also shows the Top and Bottom view of the antenna. With the help of Vector Network Analyzer, the important antenna parameter like Return Loss, VSWR and Impedance etc. are measured.

\section{MEASURED RESULTS ON VNA AND DISCUSSIONS}

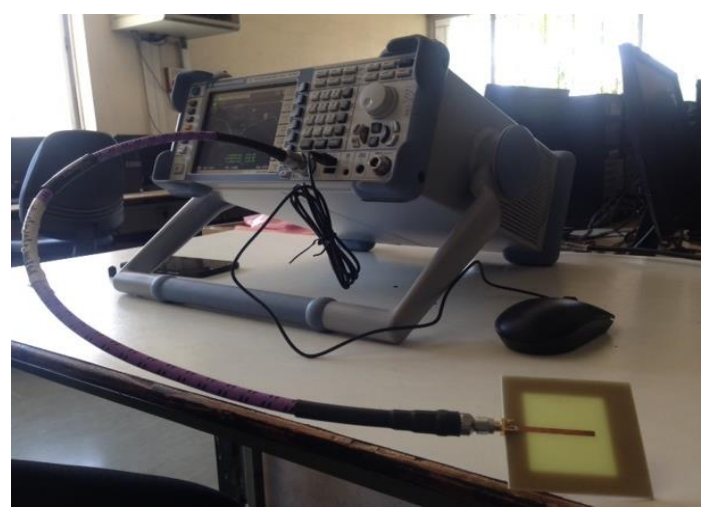

Fig.13. Measurement set up of Antenna 1

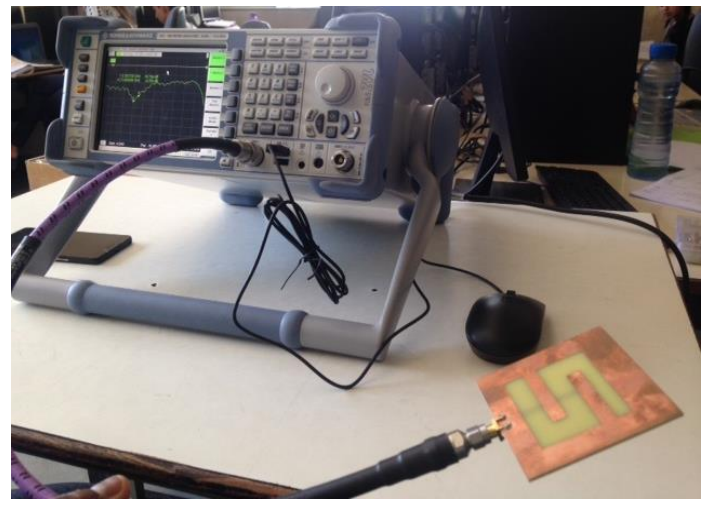

Fig.14. Measurement setup of Antenna 2

\subsection{RESULTS AND DISCUSSIONS OF MEASURED ANTENNA 1}

- Measured Return loss $\left(\mathrm{S}_{11}\right)$ of Antenna 1: The Fig.15 shows the Measured Return Loss $\left(S_{11}\right)$ of Antenna 1. The Antenna 1 resonates at $6 \mathrm{GHz}$ with Return loss of $-13.333 \mathrm{~dB}$.

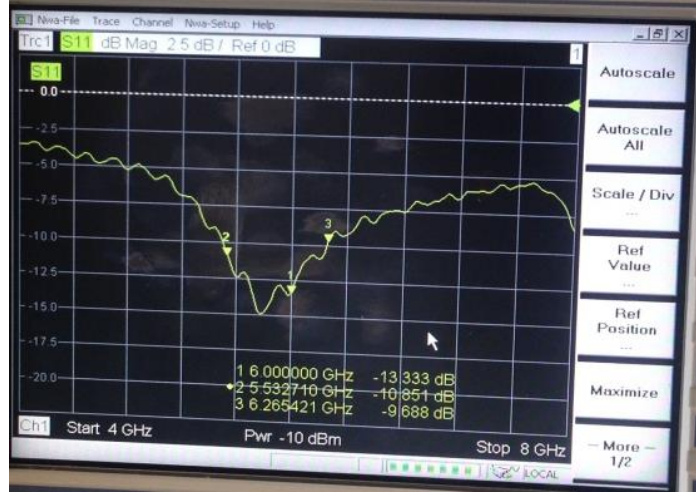

Fig.15. Measured Return Loss $\left(S_{11}\right)$ of Antenna 1

- Measured VSWR of Antenna 1: The Fig.16 shows the measured Voltage Standing Wave Ratio (VSWR) of Antenna 1 with 1.54 .

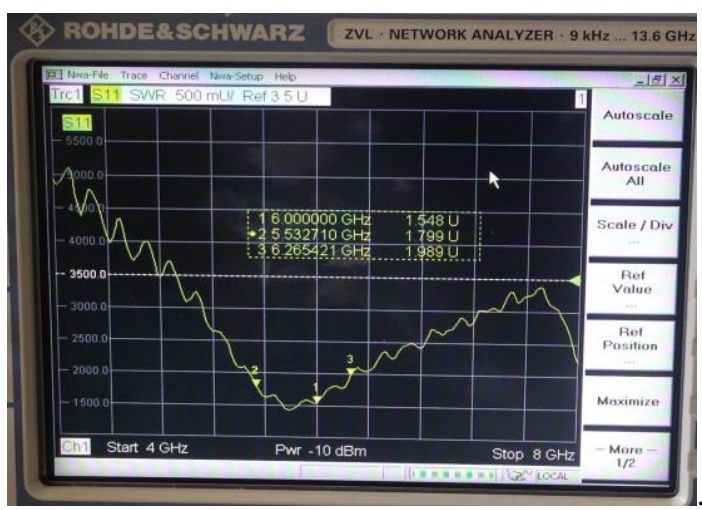

Fig.16. Measured VSWR of Antenna 1

\subsection{RESULTS AND DISCUSSIONS OF MEASURED ANTENNA 2}

- Measured Return Loss of Antenna 2: The Fig.17 shows the Measured Return Loss $\left(S_{11}\right)$ of Antenna 2. The Antenna Resonates at $5.4 \mathrm{GHz}$ with Return loss $\left(S_{11}\right)$ of $-10.60 \mathrm{~dB}$.

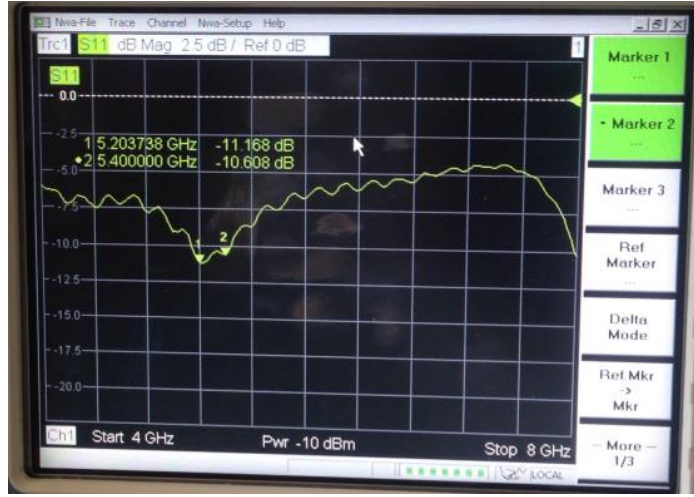

Fig.17. Measured Return Loss of Antenna 2

- Measured VSWR of Antenna 2: The Fig.18 shows the Measured Voltage Standing Wave Ratio (VSWR) of Antenna 2 with Voltage Standing Wave Ratio (VSWR) of 1.02 . 


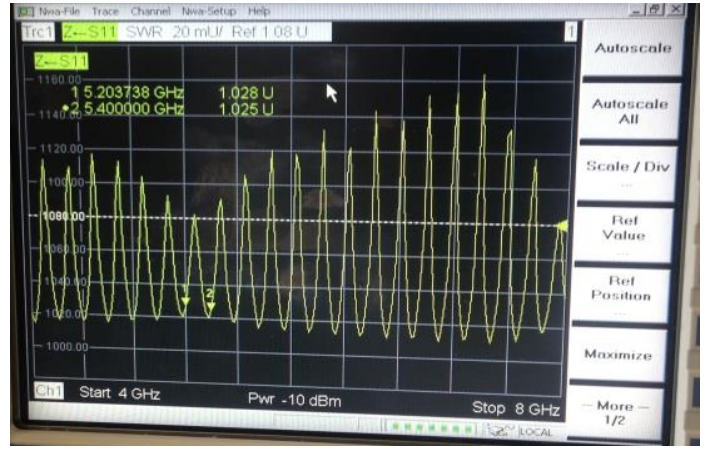

Fig.18. Measured VSWR of Antenna 2

- Measured Impedance of Antenna 2: The Fig.19 measures the impedances of Antenna 2 with $79.9 \Omega$.

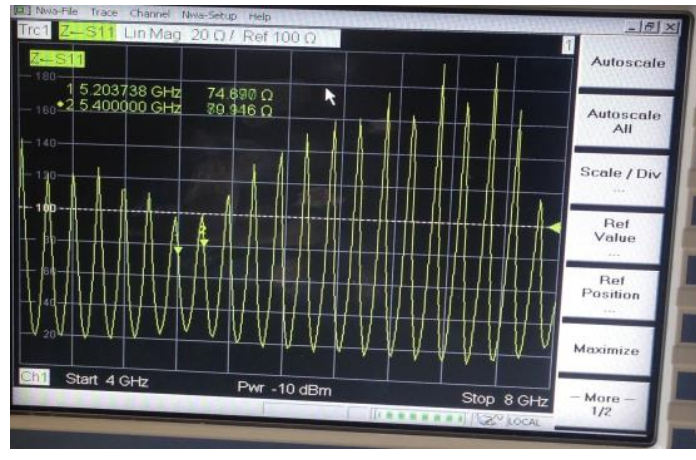

Fig.19. Measured Impedance of Antenna 2

\section{COMPARISONS PARAMETERS}

OF

ANTENNA

The Table. 2 shows the comparison of simulated results. The Table. 3 shows the comparison of simulated as well as fabricated results of circularly polarized slot patch antenna.

Table.2. Comparison of Simulated Results

\begin{tabular}{|c|c|c|}
\hline Antennas & Antenna 1 & Antenna 2 \\
\hline Resonating Frequency & $6 \mathrm{GHz}$ & $5.4 \mathrm{GHz}$ \\
\hline Return Loss (dB) & $-13.51 \mathrm{~dB}$ & $-16.64 \mathrm{~dB}$ \\
\hline Axial Ratio Bandwidth & $1.3 \mathrm{GHz}$ & $2.8 \mathrm{GHz}$ \\
& $(5.4$ to $6.7 \mathrm{GHz})$ & $(4.5$ to $7.3 \mathrm{GHz})$ \\
\hline VSWR & 1.53 & 1.58 \\
\hline Axial Ratio & $46.9 \mathrm{~dB}$ & $2.2 \mathrm{~dB}$ \\
\hline
\end{tabular}

Table.3. Comparison of Simulated as well as Fabricated Result

\begin{tabular}{|c|c|c|}
\hline Antennas & Antenna 1 & Antenna 2 \\
\hline Resonating Frequency & $6 \mathrm{GHz}$ & $5.4 \mathrm{GHz}$ \\
\hline Simulated Return Loss $(\mathbf{d B})$ & $-13.51 \mathrm{~dB}$ & $-16.64 \mathrm{~dB}$ \\
\hline Measured Return Loss $(\mathbf{d B})$ & $-13.33 \mathrm{~dB}$ & $-10.60 \mathrm{~dB}$ \\
\hline Simulated VSWR & 1.53 & 1.5 \\
\hline Measured VSWR & 1.54 & 1.02 \\
\hline
\end{tabular}

\section{CONCLUSION}

A Design of Circularly Polarized slot patch antenna is designed, simulated and made up on the FR4 epoxy substrate. This antenna covers the C-band range i.e. 4 to $8 \mathrm{GHz}$. A Microstrip slot antenna is a metal patch with a hole or slot cut out in it. The circularly polarized operation is achieved by inserting slots and stubs, which leads to a simple design and easy fabrication. The designed antenna 1 consists of Microstrip line feed and the square shaped slot is introduced in the ground plane of the antenna provides linear polarization because the axial ratio at resonant frequency of $6 \mathrm{GHz}$ is greater than $3 \mathrm{~dB}(46.9 \mathrm{~dB})$ and the designed antenna 2 has same dimensions and materials used as in antenna1 in addition two horizontal stubs are introduced from the ground plane towards the mid of the slot so that it can achieve Circular Polarization because it has simulated axial ratio at resonant frequency of $5.43 \mathrm{GHz}$ is $2.29 \mathrm{~dB}$ which is less than $3 \mathrm{~dB}$. It also has a simulated return loss bandwidth from $4 \mathrm{GHz}$ to $8 \mathrm{GHz}$. So it can be useful for C-band applications.

\section{REFERENCES}

[1] Mubarak Sani Ellis et al., "A Novel Simple and Compact Micro-strip-Fed Circularly-Polarized Wide Slot Antenna with Wide Axial Ratio Bandwidth for C-band Applications", IEEE Transactions on Antennas and Propagation, Vol. 64, No. 4, pp. 1552-1555, 2016.

[2] Constantine A. Balanis, "Antenna Theory: Analysis and Design", $3^{\text {rd }}$ Edition, Wiley-Interscience, 2005.

[3] J.Y. Sze and C.C. Chang, "Circularly Polarized Square Slot Antenna with a Pair of Inverted-L Grounded Strips", IEEE Antennas Wireless Propagation Letters, Vol. 7, pp. 149-151, 2008.

[4] J. Pourahmadazar, C. Ghobadi, J. Nourinia, N. Felegari and H. Shirzad, "Broadband CPW-Fed Circularly Polarized Square Slot Antenna with Inverted L-strip for UWB Applications", IEEE Antennas Wireless Propagation Letters, Vol. 10, pp. 369-372, 2011.

[5] N. Felegari, J. Nourinia, C. Ghobadi and J. Pourhmadazar, "Broadband CPW-Fed Circularly Polarized Square Slot Antenna with Three Inverted L-Shaped Grounded Strips", IEEE Antennas Wireless Propagation Letters, Vol. 10, pp.274-277, 2011.

[6] The Nan Chang, "Circular Polarized Antenna for 2.3-2.7 GHz WiMax Band", Microwave and Optical Technology Letters, Vol. 51, No. 12, pp. 2921-2923, 2009.

[7] J.Y. Sze, J.C. Wang and C.C. Chang, "Axial-ratio Bandwidth Enhancement of Asymmetric-CPW-Fed Circularly-Polarized Square Slot Antenna", Electronics Letters, Vol. 44, No. 18, pp. 1048-1049, 2008.

[8] J.Y. Sze and S.P. Pan, "Design of CPW-Fed Circularly Polarized Antenna with a Miniature Configuration", IEEE Antennas and Wireless Propagation Letters, Vol. 10, pp. 1465-1468, 2011.

[9] Q.X. Chu and S. Du, "A CPW-Fed Broadband Circularly Polarized Square Slot Antenna”, Microwave and Optical Technology Letters, Vol. 52, No. 2, pp. 409-412, 201. 